\title{
Acute high-altitude illness
}

\author{
R Hofmeyr, ${ }^{1,2} \mathrm{MB}$ ChB, DipPEC, DA, MMed (Anaes), FCA, FAWM; G Tölken, ${ }^{2,3} \mathrm{MA}, \mathrm{STB}$; \\ R De Decker, ${ }^{4}$ MSc, MB ChB, DCH (UK), FCPaeds (SA), Cert Med Genetics (Paeds) \\ ${ }^{1}$ Department of Anaesthesia and Perioperative Medicine, Faculty of Health Sciences, University of Cape Town, South Africa \\ ${ }^{2}$ WildMedix, Cape Town, South Africa \\ ${ }^{3}$ Mountain Rescue, Hottentots-Holland Section - Mountain Club of South Africa, Cape Town, South Africa \\ ${ }^{4}$ Department of Paediatrics and Child Health, University of Cape Town and Red Cross War Memorial Children's Hospital, Cape Town, \\ South Africa
}

Corresponding author: R Hofmeyr (ross.hofmeyr@uct.ac.za)

\begin{abstract}
A substantial proportion of South Africa (SA)'s population lives at high altitude (>1500 m), and many travel to very high altitudes $(>3500 \mathrm{~m})$ for tourism, business, recreation or religious pilgrimages every year. Despite this, knowledge of acute altitude illnesses is poor among SA doctors. At altitude, the decreasing ambient pressure proportionally decreases available oxygen (hypobaric hypoxia). This triggers both immediate respiratory compensation and gradual acclimatisation that occurs over days to weeks. Rapid ascents to altitudes above $2500 \mathrm{~m}$ can precipitate acute altitude illness, including acute mountain sickness (AMS) and high-altitude pulmonary and cerebral oedema (HAPE and HACE). The best preventive measure is gradual ascent (no more than $300-500 \mathrm{~m}$ increase in sleeping altitude per day, with additional rest days for acclimatisation for every $1000 \mathrm{~m}$ altitude gain), although chemoprophylaxis may speed acclimatisation. In the field, AMS, HAPE and HACE are diagnosed clinically. The Lake Louise Score questionnaire is used to elicit symptoms of AMS, and can be supplemented by assessing clinical signs such as tachycardia, tachypnoea, crepitations or ronchi, and ataxia. The mainstay of treatment for all but mild AMS is rapid descent to lower altitudes, which can be facilitated by administration of oxygen and drugs, including acetazolamide, dexamethasone and nifedipine, or use of a portable hyperbaric chamber.
\end{abstract}

S Afr J Med 2017;107(7):556-561. DOI:10.7196/SAMJ.2017.v107i7.12612

\section{Scenario}

Mr X - a fit and healthy 30-year-old man - joins a group climbing Mount Kilimanjaro, hoping to reach Uhuru Peak (5 895 m above mean sea level). His 6-day, 5-night expedition is following the Rongai route, approaching from the northern side of Kilimanjaro. After flying in from his home at sea level in South Africa (SA), they begin their trek near the Kenyan border at $1900 \mathrm{~m}$. Despite no previous experience at altitude, he shows no signs of struggling with the ascent, and easily copes during the deliberately slow hikes of the first 3 days to reach Kikelewa Caves (3 $675 \mathrm{~m}$ ). However, on arrival at Mawenzi Tarn camp (4 $300 \mathrm{~m})$ at the end of the hot 4th day, Mr X complains of a headache, dizziness and nausea.

The local lead guide offers $\mathrm{Mr}$ X $800 \mathrm{mg}$ oral ibuprofen to ease the headache and encourages him to rest. Having no appetite, Mr X skips dinner that night, but does take care to remain well hydrated. In the morning his headache has resolved, but he complains of having had fitful sleep. Routine screening by the guides shows elevated resting breathing and heart rates (respiratory rate 28/min.; heart rate 120/ $\mathrm{min}$.). A portable fingertip pulse oximeter shows that his peripheral arterial oxygen saturation $\left(\mathrm{SpO}_{2}\right)$ has dropped to $64 \%$. The guides are nevertheless anxious to push on, and $\mathrm{Mr} \mathrm{X}$ continues with the group to Kibo Huts (4 $714 \mathrm{~m})$.

During the day, his headache returns, and he feels lethargic and breathless. Nonetheless, with his bucket-list goal in sight, he participates in the final summit preparations. The group leaves camp for the summit at midnight. During the relentless climb to the crater rim $(5680 \mathrm{~m}), \mathrm{Mr}$ X feels increasingly cold, and develops ataxia and tunnel vision. Amid the tired party in the predawn light, his deterioration remains unnoticed. At Gilman's Point on the summit ridge, the group stops for a brief rest. Mr X is disorientated, has lost fine motor control, and speaks incoherently before he collapses.
By this point, the guides have discovered that you are a doctor, and turn to you for help. What is your assessment and action plan? Thinking back, if you were the expedition's doctor, would you have intervened earlier?

\section{Background}

Although SA is not traditionally associated with high-altitude climbing, the country is blessed with many beautiful mountain ranges. An increasingly substantial proportion of the population takes part in recreational climbing and mountaineering, both locally and abroad. Many also travel to high-altitude regions worldwide for simple tourism, business or religious pilgrimages. ${ }^{[1]}$ Globally, it has been estimated that $>35$ million people travel to altitudes of greater than $3000 \mathrm{~m}$ per annum. ${ }^{[2]}$ In southern Africa, several large metropolitan areas are above $1500 \mathrm{~m}$, and peaks of up to $3482 \mathrm{~m}$ are regularly ascended. Despite this, there is generally a poor level of recognition of the implications and risks of high altitude for healthy travel and recreation among SA doctors. ${ }^{[3]}$

High altitude is defined as greater than $1500 \mathrm{~m}$ above sea level. At this level, the physiological implications of decreasing ambient pressure (hypobaria) and corresponding decrease in the partial pressure of oxygen (hypoxia) are regularly apparent, although they do not have pathological consequences in healthy individuals. Altitude between $1500 \mathrm{~m}$ and $3500 \mathrm{~m}$ is referred to by some authors as intermediate, and it is within this range that altitude-related illnesses begin to manifest. Very high altitude is defined as being above $3500 \mathrm{~m}$, where simple physiological compensation is no longer sufficient to maintain oxygenation, and gradual acclimatisation is required. Exposure to extreme altitudes (above $5500 \mathrm{~m}$ ) without acclimatisation is highly likely to cause severe illness. The summit of Kilimanjaro (5 $895 \mathrm{~m})$ has an ambient pressure of approximately $47 \mathrm{kPa}$ (less than half of 
sea-level pressure), resulting in arterial oxygen tension $\left(\mathrm{PaO}_{2}\right)$ of only $6 \mathrm{kPa}$, even with ideal acclimatisation (Fig. 1). Blood gases drawn near the summit of Mount Everest have demonstrated the lowest recorded oxygen partial pressures in healthy subjects, with a $\mathrm{PaO}_{2}$ range of $2.55-3.93 \mathrm{kPa}^{[4]}$

\section{Acute high-altitude illnesses Physiology of altitude, acclimatisation and aetiology of high-altitude illnesses}

The complex physiological response to altitude is not yet fully understood and beyond the scope of this article. While the concentration (proportion) of oxygen in the atmosphere remains remarkably consistent at $20.9 \%$, the drop in ambient pressure with increasing altitude results in a directly corresponding decline in the partial pressure $\left(\mathrm{PO}_{2}\right)$. The reduction in inspired $\mathrm{PO}_{2}$ is compounded by the unaltered saturated vapour pressure of water in the alveoli, and the unaltered (or increased) metabolic production of carbon dioxide. Although rapid and profound compensation through increased minute ventilation is possible, the inevitable physiological consequence of ascent to high altitude is hypobaric hypoxia. ${ }^{[5]}$ Over time, the combination of hypoxia and hyperventilation-induced respiratory alkalosis triggers a cascade of physiological effects, leading to acclimatisation. These include increased renal excretion of bicarbonate, a 2-3-DPG-mediated shift in the oxygen-haemoglobin dissociation curve, erythropoiesis, and angioneogenesis at the capillary level.

Over a period of days to weeks, the body gradually adjusts to optimise oxygen delivery to the tissues, maintaining the oxygen cascade from atmosphere to mitochondrion. Indeed, given sufficient time to acclimatise, the human organism is remarkably capable of function despite low $\mathrm{PaO}_{2}$, as is eloquently demonstrated by a visit to any paediatric cardiology ward, where children with cyanotic congenital heart disease play alongside their well-oxygenated counterparts. However, a sudden decrease in $\mathrm{PaO}_{2}$ without adequate time for acclimatisation is highly likely to manifest as acute illness. In

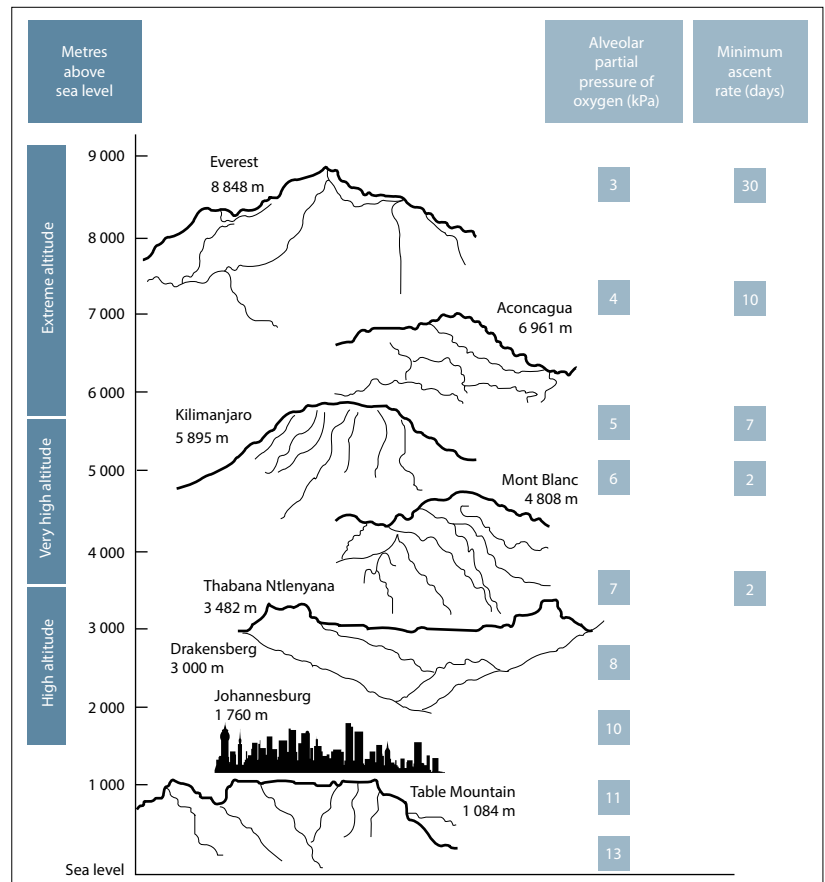

Fig. 1. Altitudes of well-known peaks and African locations, with the approximate alveolar partial pressure of oxygen and minimum duration of safe acclimatisation (SAMJ, ${ }^{[3]}$ with permission). the context of ascent to altitude, simple respiratory compensation is no longer sufficient from $\sim 3500 \mathrm{~m}$. This explains the sudden increase in high-altitude illnesses (HAIs) and particularly acute mountain sickness (AMS) seen above this point (Table 1). The exact aetiology of AMS, widely considered a precursor to more severe altitude illnesses, is also poorly understood. ${ }^{[6-9]}$

\section{Acute mountain sickness, high-altitude cerebral oedema and high-altitude pulmonary oedema}

Altitude illness is characterised by tissue hypoxia and oedema, particularly in the brain and lungs. This is the result of a complex interplay of hydrostatic pressure differences due to hypoxic vasomotor changes, and increased capillary permeability through release of agents such as vascular endothelial growth factor and hypoxia-inducible factor 1-alpha (HIF-1- $\alpha$ ). The predominant symptom complex includes headaches, nausea and loss of appetite, dizziness or lightheadedness, fatigue or weakness, and sleep disturbance. It is diagnosed clinically, because of the typical lack of advanced investigations in the context of high-altitude expeditions and the multifactorial nature of the disease (see 'Clinical diagnosis' below). Similarly, high-altitude pulmonary oedema (HAPE) and high-altitude cerebral oedema (HACE) are commonly considered advanced forms of AMS and diagnosed on clinical signs, but can and do occur independently.

Onset of altitude-related illness is indiscriminate, and can occur at relatively low altitudes (instances of AMS have been reported at as low as $2000-2500 \mathrm{~m}$ ), but is most common after rapid ascent to above $3500 \mathrm{~m}$. Prior safe ascent to altitude is no guarantee of avoiding AMS on subsequent exposure. ${ }^{[8]}$ Physical fitness, gender and youth are not reliably predictive, although there is a protective association with increased age. A genetic predisposition is being researched. ${ }^{[10-12]}$

Typical altitudes for onset of development of HAPE and HACE are $3000 \mathrm{~m}$ and $4500 \mathrm{~m}$, respectively. While AMS is usually diagnosed within a day of reaching a new elevation, HAPE and HACE (considered to be advanced manifestations or complications of AMS) commonly present after more than 24 hours at altitude. ${ }^{[6,13,14]}$

\section{Prevention of high-altitude illness}

AMS, HACE and HAPE are the most commonly encountered altitudeinduced illnesses during ascent above $2500 \mathrm{~m}$, but are also nearly entirely preventable. ${ }^{[6,7]} \mathrm{Up}$ to altitudes of $6000 \mathrm{~m}$, the occurrence of HAI is the direct result of inadequate acclimatisation. Depending on individual physiology and ascent profile, up to $70 \%$ of mountaineers develop symptoms of AMS. ${ }^{[14]}$ The foremost approach to AMS, HAPE and HACE is prevention through education, supporting conservative ascent profiles to allow sufficient acclimatisation, and promoting adequate hydration, caloric intake and exposure protection. ${ }^{[3,14]}$ Within the African context, AMS is very prevalent on Kilimanjaro owing to the lack of a sufficiently long approach trek and rapid ascent profiles followed by local tour operators. ${ }^{[15]}$ Kilimanjaro climbs of $<7$ days' duration are therefore considered 'high risk' profiles (Table 2), which contribute to the 3 - 8 reported but avoidable deaths out of about 30000 trekkers on the mountain each year. ${ }^{[3,13,15-19]}$

The single most effective method of prevention is gradual acclimatisation, paired with adequate hydration and caloric intake. After reaching an elevation of $2500-3000 \mathrm{~m}$, sleeping altitudes should not increase by more than $300-500 \mathrm{~m}$ each day, with a rest day at the same altitude for each $1000 \mathrm{~m}$ ascent. ${ }^{[3,13,14]}$ Sleeping elevation contributes more significantly to adequate acclimatisation than physical exercise and altitude gain during the day. ${ }^{[13]}$ Where terrain necessitates occasional elevation gains in excess of suggested safe ascent 
Table 1. Consequences of acute exposure to high altitude

\begin{tabular}{|c|c|c|}
\hline $\begin{array}{l}\text { High altitude } \\
(1500-3500 \mathrm{~m})\end{array}$ & $\begin{array}{l}\text { Very high altitude } \\
(3500-5500 \mathrm{~m})\end{array}$ & $\begin{array}{l}\text { Extreme altitude } \\
(5500-8850 \mathrm{~m})\end{array}$ \\
\hline $\begin{array}{l}\text { HAI occurs with rapid ascent } \\
\text { above } 2500 \mathrm{~m}\end{array}$ & $\begin{array}{l}\text { Most common range for HAI } \\
\text { (AMS, HAPE, HACE) }\end{array}$ & $\begin{array}{l}\text { Abrupt ascent always causes } \\
\text { severe HAI }\end{array}$ \\
\hline $\begin{array}{l}\downarrow \text { Exercise performance } \\
\uparrow \text { Ventilation }\end{array}$ & $\begin{array}{l}\text { Requires acclimatisation for } \\
\text { physical effort to be tolerated }\end{array}$ & $\begin{array}{l}\text { Progressive physiological } \\
\text { deterioration outstrips } \\
\text { acclimatisation }\end{array}$ \\
\hline $\begin{array}{l}\text { Minor decrease in } \mathrm{SpO}_{2} \\
\text { (usually } \geq 90 \% \text { ) }\end{array}$ & $\mathrm{SpO}_{2}: 75-85 \%$ & $\begin{array}{l}\mathrm{SpO}_{2}: 55 \text { - } 75 \% \\
\text { Severe hypocarbia }\end{array}$ \\
\hline $\mathrm{PaO}_{2}: 7-10 \mathrm{kPa}$ & $\mathrm{PaO}_{2}: 5-8 \mathrm{kPa}$ & $\mathrm{PaO}_{2}: 3.5-5 \mathrm{kPa}$ \\
\hline $\begin{array}{l}\text { Severe hypoxia unlikely in the } \\
\text { absence of underlying illness } \\
\text { or HAPE }\end{array}$ & $\begin{array}{l}\text { Extreme hypoxia may occur } \\
\text { during sleep, exercise or illness }\end{array}$ & $\begin{array}{l}\text { Always requires } \\
\text { acclimatisation to avoid illness }\end{array}$ \\
\hline
\end{tabular}

Table 2. Risk categories for AMS (Wilderness Medical Society consensus guidelines) ${ }^{[13]}$

\begin{tabular}{|c|c|}
\hline Risk category & Description \\
\hline Low & $\begin{array}{l}\text { Individuals with no prior history of altitude illness and ascending to } \\
\leq 2800 \mathrm{~m} \\
\text { Individuals taking } \geq 2 \text { days to arrive at } 2500 \text { - } 3000 \mathrm{~m} \text { with subsequent } \\
\text { increases in sleeping elevation }<500 \mathrm{~m} / \text { day and an extra day for } \\
\text { acclimatisation every } 1000 \mathrm{~m}\end{array}$ \\
\hline Moderate & $\begin{array}{l}\text { Individuals with a prior history of AMS and ascending to } 2500-2800 \mathrm{~m} \\
\text { in } 1 \text { day } \\
\text { No history of AMS and ascending to }>2800 \mathrm{~m} \text { in } 1 \text { day } \\
\text { All individuals ascending }>500 \mathrm{~m} / \text { day (increase in sleeping elevation) at } \\
\text { altitudes }>3000 \mathrm{~m} \text { but with an extra day for acclimatisation every } 1000 \mathrm{~m}\end{array}$ \\
\hline High & $\begin{array}{l}\text { Individuals with a history of AMS and ascending to }>2800 \mathrm{~m} \text { in } 1 \text { day } \\
\text { All individuals with a prior history of HACE } \\
\text { All individuals ascending to }>3500 \mathrm{~m} \text { in } 1 \text { day } \\
\text { All individuals ascending }>500 \mathrm{~m} \text { /day (increase in sleeping elevation) } \\
>3000 \mathrm{~m} \text { without extra days for acclimatisation } \\
\text { Very rapid ascents (e.g. }<7 \text { day ascents of Mount Kilimanjaro) }\end{array}$ \\
\hline
\end{tabular}

profiles, additional rest days must be incorporated into the itinerary to keep the average rate of ascent within safe parameters. ${ }^{[13]}$ Adequate hydration (estimated in the field by maintaining frequent micturition and keeping urine colourless) is imperative to allow the elimination of bicarbonate necessary for physiological acclimatisation. Although loss of appetite is a common feature, care should be taken to consume sufficient carbohydrate-rich meals to compensate for increased metabolic loads and improve the respiratory exchange ratio. ${ }^{[5]}$ Minimising loss of body fat has the benefit of helping cope with low temperatures at high altitude; a more significant risk of poor nutrition is subsequent loss of muscle mass.

\section{Clinical diagnosis: Symptoms and the Lake Louise symptom score}

Secondary only to proper acclimatisation, early recognition of AMS is key to allowing individuals to take simple corrective measures before the risks of complications increase.

AMS is defined by the presence of a highaltitude headache (onset of headache within 24 hours of ascent to above $2500 \mathrm{~m}$ ) and at least one other symptom of sleep disorder, gastrointestinal upset (nausea, vomiting or loss of appetite), dizziness or lightheadedness, and lethargy, fatigue or weakness. Frequently, this is accompanied by peripheral oedema, shortness of breath and tachycardia, which often worsen at night. ${ }^{[8,14,20]}$ Being nonspecific, these symptoms are often mistaken for non-consequential ailments such as flu, a cold or dehydration - all common travel complaints. ${ }^{[6]}$ However, AMS should always be assumed until proven otherwise. ${ }^{[3]}$ Although the diagnosis of AMS is symptomatic and clinical, determining its severity is largely subjective. As participants focus on expedition goals, symptoms are often under-reported, which leads to an underestimation of severity. This can result in a lack of appropriate medical intervention, such as the climber being advised to discontinue an ascent. Furthermore, under-reporting of AMS symptoms such as severe headaches and drowsiness may lead to the early warning signs of HACE being missed.

To objectively standardise diagnosis and quantify the severity of AMS, the Lake Louise Symptom Questionnaire and Clinical Scores were established (LLSQ and LLS-C, respectively). This allows for both monitoring of symptoms by lay mountaineers, and field research of AMS by expedition doctors (Fig. 2).$^{[13,20,21]}$ Each of the five symptoms and three clinical signs are assigned a severityrelated score from 0 (absent) to 3 (severe or incapacitating). Inability to stand for an ataxia test carries a score of 4 . AMS is considered present with a score of $\geq 3$ for the LLSQ, and $>5$ for the LLS-C. It is advisable that the LLSQ is performed twice daily by team members (in the mornings after waking, and in the evenings once settled into camp), and the LLS-C independently by the team physician.

For HAPE, AMS symptoms are typically aggravated by dyspnoea at rest or with light workloads, impaired exercise performance, coughing, tachycardia, subjective chest tightness, ronchi/rales, cyanosis, mild fever and (in extreme cases) foamy bloodstained sputum..$^{[7,14,22]}$ Importantly, HAPE may occur without the precedence of AMS symptoms. ${ }^{[23]}$

HACE commonly presents with severe headaches that remain unresponsive to analgesics, ataxia, altered level of consciousness and loss of insight. A simple field test for ataxia is to observe an individual walking heel-to-toe on a straight line drawn on the ground. ${ }^{[14,24]}$

Complications of AMS in the form of HAPE or HACE may be lethal, and early clinical recognition is vital in austere environments to allow suitable and effective treatment. Research into the use of point-ofcare ultrasound scans of the lung and optic nerve sheath diameter is a promising new modality for screening, prediction and early diagnosis of HAPE and HACE respectively, but is still at the experimental stage. ${ }^{[25,26]}$ 


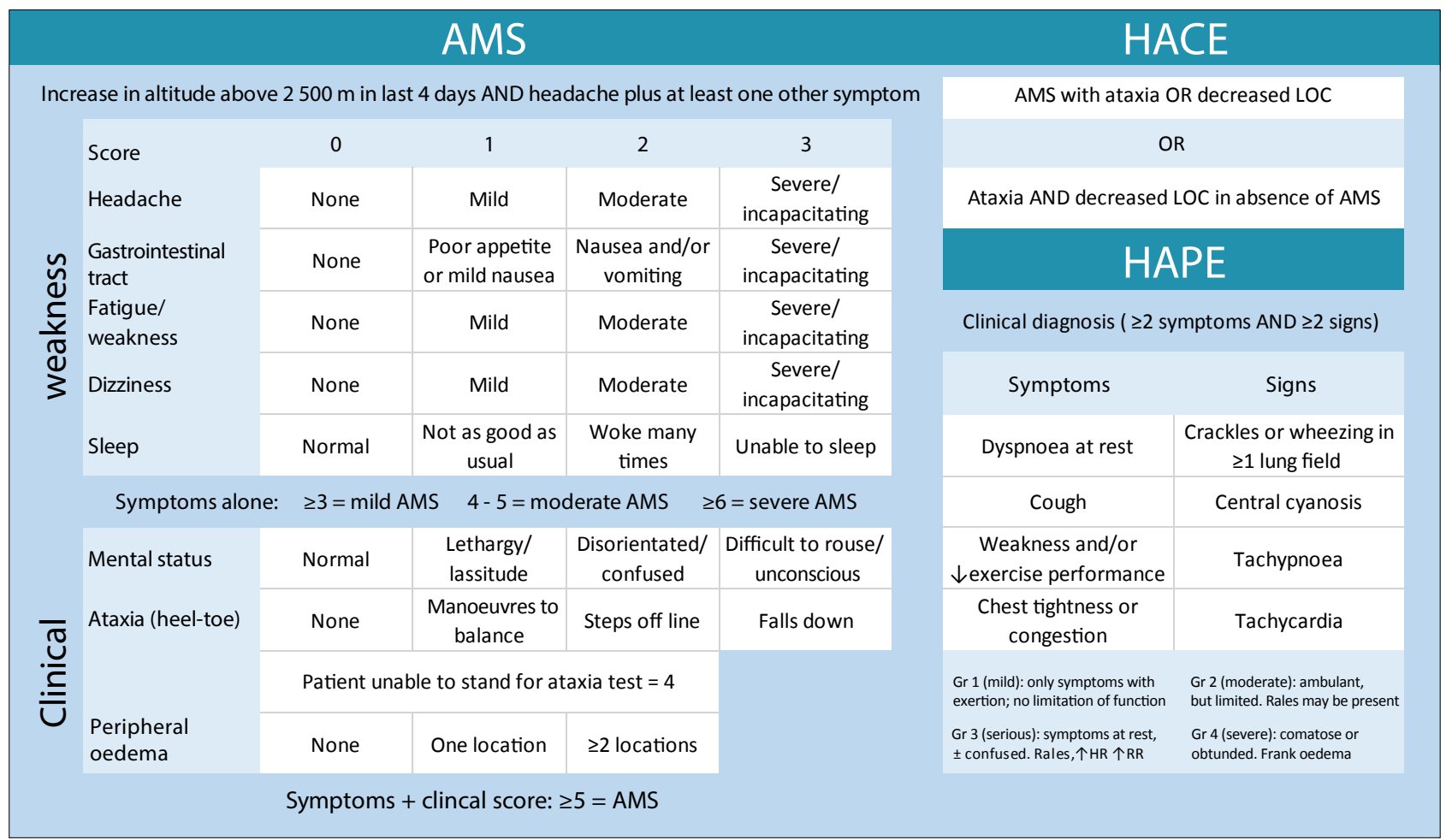

Fig. 2. Diagnostic criteria for acute HAI, incorporating the Lake Louise Symptom and Clinical Scores. Graphic representation from WildMedix Mountain Expedition Medicine course materials, used with permission. (AMS = acute mountain sickness; HAPE = high-altitude pulmonary oedema; HACE = high-altitude cerebral oedema; $\mathrm{Gr}=$ grade; $L O C=$ level of consciousness; $H R=$ heart rate; $R R=$ respiratory rate.)

\section{Chemoprophylaxis}

Although widely advised, the prophylactic intake of the carbonic anhydrase inhibitor acetazolamide (Diamox 125 - $250 \mathrm{mg}$ twice daily) is debated in the literature. ${ }^{[2,13,27]}$ By increasing renal bicarbonate excretion, it can improve the rate of acclimatisation, but has limited or no effect if the ascent profile is too rapid. ${ }^{[7,14,19,28]}$ Acetazolamide can result in side-effects that mimic AMS (nausea, vomiting, anorexia and dizziness) and blurred vision, severe paraesthesia and odd tastes in the mouth. Individuals wishing to take acetazolamide for high-risk ascent profiles should ideally take several test doses at home before the ascent. It is contraindicated for use in diabetes and sulphonamide allergy. ${ }^{[13,14]}$

Use of dexamethasone as prophylaxis $(2 \mathrm{mg}$ 6-hourly or $4 \mathrm{mg}$ 12-hourly) is similarly debated, mainly because of concerns regarding masking symptoms of AMS, and its side-effect profile. ${ }^{[13,28]}$ However, it is used selectively in groups making very short rapid high-altitude ascents, such as rescue teams.

Ibuprofen has been shown in randomised controlled trials to be more effective than placebo in decreasing the incidence of AMS, but this has been contested in light of the fact that it reduces headache, which is essential for the clinical diagnosis. ${ }^{[29,30]}$ Alternative prophylactic substances such as ginkgo bilo- ba and coca-derived products have shown contradictory results. ${ }^{[13,29,31]}$

Individuals at elevated risk or with previous episodes of HAPE can be treated with nifedipine $(20 \mathrm{mg}$ slow-release preparation 8-hourly) or sildenafil (20 - 50 mg 8-hourly) prophylactically. As both drugs can cause postural hypotension, a trial at home before departure is recommended.

\section{Field management}

For mild to moderate symptoms of AMS (LLSQ 3 - 5 or LLS-C $>5$ ), primary treatment takes the form of rest days without any

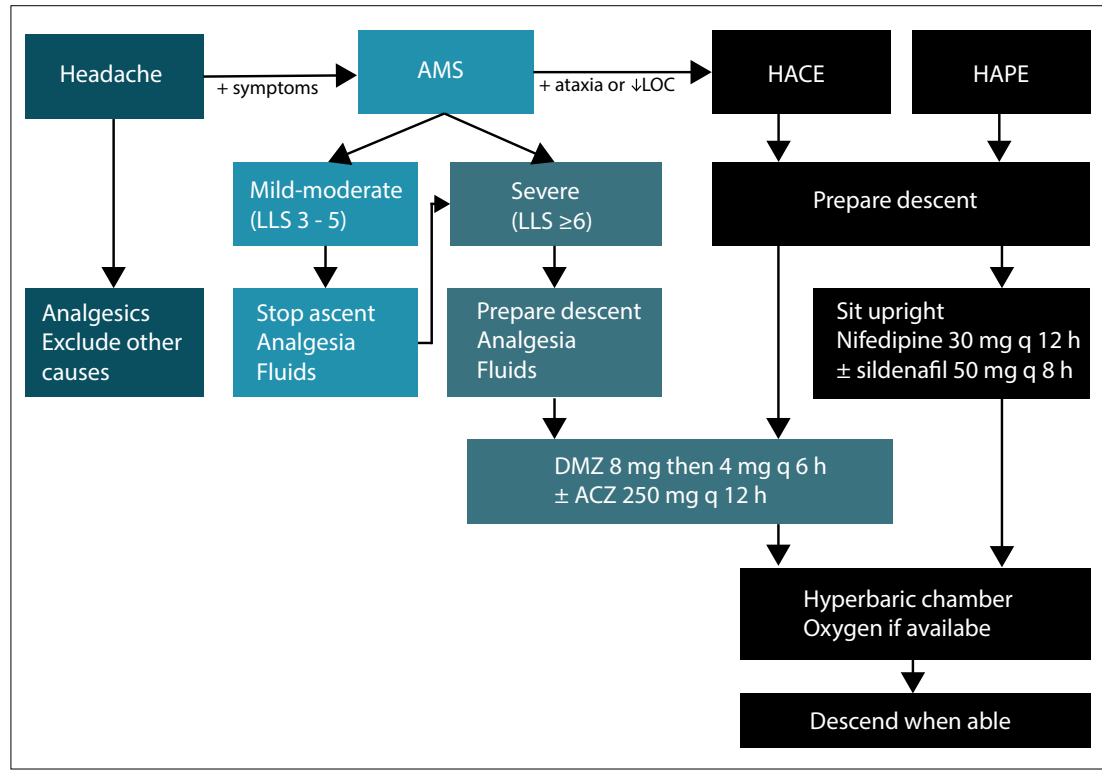

Fig. 3. Flow diagram for the management of acute high-altitude illness (adapted from Davis et al. ${ }^{[35}$ ). (AMS = acute mountain sickness; $L O C=$ level of consciousness; $D M Z=$ dexamethasone (first dose intravenously then intramuscularly); $A C Z=$ oral acetazolamide; nifedipine = sustained-release; HAPE = high-altitude pulmonary oedema; HACE = high-altitude cerebral oedema; $L L S=$ Lake Louise Score.) 
physical exertion at the current altitude, until all symptoms resolve ${ }^{[13]}$ (Fig. 3). Additional supportive treatment with oral anti-emetics, simple analgesia, adequate hydration and sleeping with a slightly elevated upper body are effective. If symptoms do not improve within 24 hours, the patient should descend to an altitude where the symptoms are not present. Acetazolamide ( $250 \mathrm{mg}$ orally twice daily) may be administered (particularly if symptoms worsen and descent is delayed). ${ }^{[13]}$ Should the presenting altitude be situated in a 'terrain trap' - a location which demands some ascent before descent can be commenced - then early descent before exacerbation of symptoms must be considered. Once symptoms have progressed further, a terrain trap may preclude descent, leading to a serious or fatal outcome. Other scenarios that may hamper immediate descent worsening weather, other injuries or difficult terrain - deserve the same considerations.

In the presence of severe symptoms (LLSQ score $>5$ ), HACE should be suspected and integrated into the treatment plan. ${ }^{[3]}$ Immediate action takes the form of refraining from any further ascent, administration of oxygen if available, enforced rest and protection against cold. Descent by any safe means should be initiated. Supporting treatment as described may be provided. Dexamethasone should be considered in severe AMS and used in all cases of HACE ( $8 \mathrm{mg}$ orally every 6 hours, or $4 \mathrm{mg}$ intramuscularly/intravenously every 4 hours). ${ }^{[13,14]}$ As soon as the patient's condition allows

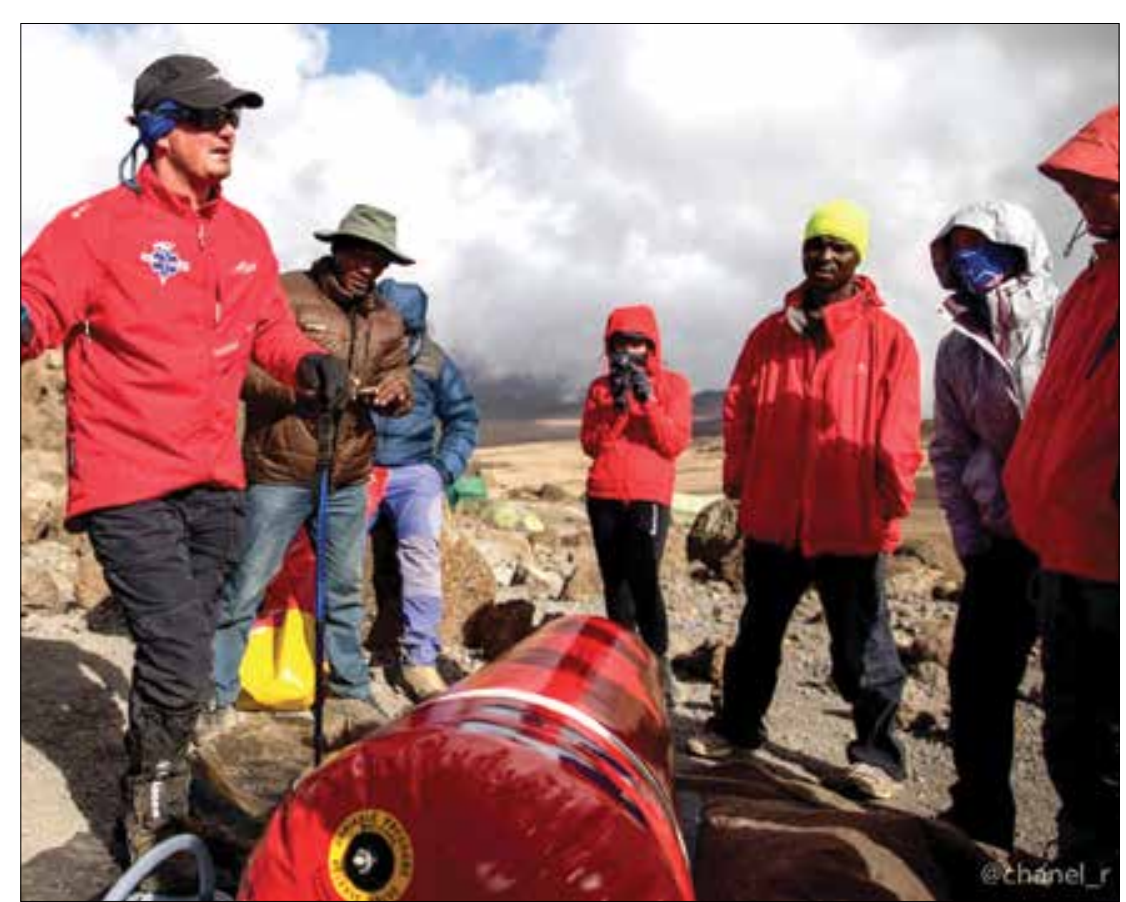

Fig. 4. The authors training expedition doctors and mountain guides discussing the use of a portable

hyperbaric chamber at $4800 \mathrm{~m}$ on Kilimanjaro (photo: Dr Chanèl Rossouw, with permission).

(able to safely navigate the terrain), descent must be started, going down to the altitude at which the patient was last completely well, or if that altitude is unknown, at least 500 - $1000 \mathrm{~m} \cdot{ }^{[6,28,32]}$ Descent should avoid terrain traps and the patient should not carry any loads. If descent is delayed because of environmental conditions, a portable hyperbaric chamber (PHC) is strongly advised. ${ }^{[3,14]} \mathrm{A}$ PHC is an inflatable, lightweight, airtight capsule into which a patient is placed while the capsule is inflated by a foot pump to increase the internal pressure, simulating descent (Fig. 4). Pumping must be continuous to maintain air flow, making the use of a PHC extremely strenuous at high altitude. PHC treatment is to be continued for 2 - 4 hours to stabilise severely ill patients before descending. ${ }^{[2,33]}$ PHCs are rare in the African context, but are carried by some high-altitude expeditions.

For HAPE patients, immediate rest (with the upper body elevated), protection against cold, supplementary $\mathrm{O}_{2}$, acetazolamide and dexamethasone followed by slow-release nifedipine (20 mg orally) are recommended. This can be supplemented with sildenafil $(50 \mathrm{mg}$ orally) and inhaled salbutamol or salmeterol, which improves pulmonary interstitial oedema by stimulating the sodium/potassium pump. Antidiuretics should be avoided, and use of a PHC should be considered, if available.

All patients with severe AMS, HAPE or HACE should be evacuated to lower altitudes, preferably by passive evacuation using a stretcher, beast of burden or heli- copter. Adequate treatment equipment must accompany the patient during descent. The patient must be continuously monitored for deterioration, and must be safely managed and assisted in navigating the terrain once ambulant. This task should be performed by adequately trained and equipped medical personnel, rather than being deferred to guides or porters.

Re-ascent should not be considered until patients are completely asymptomatic after cessation of treatment. ${ }^{[13]}$ Should it be difficult to differentiate between AMS, HAPE and HACE, treat for all three conditions. However, care must be taken in HACE to not inadvertently lower mean arterial pressure by using nifedipine, which could worsen cerebral oxygenation by lowering cerebral perfusion pressure. ${ }^{[8,33,34]}$

\section{Scenario resolution}

Faced with Mr X's collapse on the summit ridge, you regret not speaking up at Mawenzi Tarn, $1500 \mathrm{~m}$ below, although the differential diagnosis for his symptoms at that stage was broad, including simple dehydration or heat stroke. You recognise that the combination of headache, loss of appetite and poor sleep already constituted a clinical diagnosis of mild AMS. At Kibo, his breathlessness and lethargy should have alerted the expedition leadership that he should descend, or at least commence treatment for AMS. In the setting of his acute collapse, you recognise that the differential includes exhaustion, hypothermia, hypoglycaemia, dehydration and various other medical conditions, but a presumptive diagnosis of severe AMS and high-altitude cerebral oedema must be made. Knowing that only the most rudimentary field rescue facilities and no helicopter are available, which will undoubtedly delay definitive medical care, you urgently administer doses of oral acetazolamide and intravenous dexamethasone as well as supplemental oxygen from the guide's cylinder, and initiate a rapid descent. Foregoing the summit, you monitor his condition on an ongoing basis. By the time $\mathrm{Mr} \mathrm{X}$ reaches Kibo he is able to walk unaided, and you push on down to Horombo Huts (3 $700 \mathrm{~m})$. Other than tiredness and a slight cough, $\mathrm{Mr} \mathrm{X}$ is feeling well. He thanks you for sacrificing your summit bid to assist him and affirms his intention to return to the mountain again with a more prudent acclimatisation profile.

1. Basnyat B. High altitude pilgrimage medicine. High Alt Med Biol 2014;15(4):434-439. http://dx.doi.org/10.1089/ham.2014.1088 2. Berghold F. Drug abuse in the mountains. In: Vsicor G, Ricart A, Leal C, eds. Health and Height: Proceedings of the 5th World A, Leal C, eds. Health and Height: Proceedings of the 5th World Barcelona: Univarsitat de Barcelona, 2003:99-106. 
3. Hofmeyr R, Meyer W, James M, De Decker R. Recognising and mitigating the risk of altitude-related Hofmeyr R, Meyer W, James M, De Decker R. Recognising and mitigating the risk of altitude-
illness. S Afr Med J 2016;106(9):834-835. http://dx.doi.org/10.7196/SAMJ.2016.v106i9.11389

4. Grocott MP, Martin DS, Levett DZ, et al. Arterial blood gases and oxygen content in climbers on Moun 4. Grocott MP, Martin DS, Levett DZ, et al. Arterial blood gases and oxygen content in clim
Everest. N Engl J Med 2009;360(2):140-149. http://dx.doi.org/10.1056/NEJMoa0801581

5. West JB. Acclimatization and tolerance to extreme altitude. J Wilderness Med 1993:4(1):17-26. 5. West JB. Acclimatization and tolerance to extreme altitude. J Wilderness Med 1993;4(1):17-26.
6. Johnson C, Anderson S, Dallimore J, et al. Oxford Handbook of Expedition and Wilderness Medicine. 6. Johnson C, Anderson S, Dallimore J, et al. Oxford Handbook of Expedition and Wilderness Medicine.
2nd ed. Oxford: Oxford University Press, 2015.

7. Gallagher SA, Hackett PH. High-altitude illness. Emerg Med Clin North Am 2004;22(2):329-355. http://dx.doi.org/10.1016/j.emc.2004.02.001

Hackett PH, Roach RC. High-altitude illness. N Engl J Med 2001;345(2):107-114. http://dx.doi.org/10.1056/NEJM200107123450206

9. Bailey DM, Willie CK, Hoiland RL, et al. Surviving without oxygen: How low can the human brain go? High Alt Med Biol 2016;18(1):73-79. http://dx.doi.org/10.1089/ham.2016.008

10. MacInnis MJ, Koehle MS, Rupert JL. Evidence for a genetic basis for altitude illness: 2010 update. High Alt Med Biol 2010;11(4):349-368. http://dx.doi.org/10.1089/ham.2010.1030

11. MacInnis MJ, Rupert JL. 'Ome on the range: Altitude adaptation, positive selection, and Himalayan genomics. High Alt Med Biol 2011;12(2):133-139. http://dx.doi.org/10.1089/ham.2010.109

12. MacInnis MJ, Widmer N, Timulsina $\mathrm{U}$, et al. A preliminary genome-wide association study of acute mountain sickness susceptibility in a group of Nepalese pilgrims ascending to $4380 \mathrm{~m}$. High Alt Med Biol 2015;16(4):290-297. http://dx.doi.org/10.1089/ham.2015.0065

13. Luks AM, McIntosh SE, Grissom CK, et al. Wilderness Medical Society practice guidelines for the prevention and treatment of acute altitude illness: 2014 update. Wilderness Environ Med 2014;25(Suppl 4):S4-S14. http://dx.doi.org/10.1016/j.wem.2014.06.017

14. Küpper T, Gieseler U, Angeline C, et al. Consensus Statement of the Union Internationale des Association d'Alpinisme Medical Commission. Vol. 2. Emergency Field Management of Acute Mountain Sickness, High Altitude Pulmonary Edema, and High Altitude Cerebral Edema. Berne: UIAA, 2012.

15. Shah NM, Windsor JS, Meijer H, Hillebrandt D. Are UK commercial expeditions complying with wilderness medical society guidelines on ascent rates to altitude? J Travel Med 2011;18(3):214-216. http:// dx.doi.org/10.1111/j.1708-8305.2011.00511.x

16. Karinen H, Peltonen J, Tikkanen H. Prevalence of acute mountain sickness among Finnish trekkers on Mount Kilimanjaro, Tanzania: An observational study. High Alt Med Biol 2008;9(4):301-306. http:// dx.doi.org/10.1089/ham.2008.1008

17. Jackson SI, Varley J, Sellers C, et al. Incidence and predictors of acute mountain sickness among trekkers on Mount Kilimanjaro. High Alt Med Biol 2010;11(3):217-222. http://dx.doi.org/10.1089/ham.2010.1003

18. Davies AJ, Kalson NS, Stokes S, et al. Determinants of summiting success and acute mountain sickness on Mt Kilimanjaro (5 $895 \mathrm{~m}$ ). Wilderness Environ Med 2009;20(4):311-317. http://dx.doi. org/10.1580/1080-6032-020.004.0311

19. Nicol LG, Evans HE. Walk high, sleep low: An observational cohort study of altitude symptoms an physiological profiles over a 6 day ascent of Mount Kilimanjaro. Wilderness Environ Med 2014:25(3):354. http://dx.doi.org/10.1016/j.wem.2014.01.010
20. Roach R, Bartsch P, Oelz O, Hackett PH. The Lake Louise acute mountain sickness scoring system. In: Sutton JR, Houston CS, Coates G, eds. Hypoxia and Molecular Medicine. Burlington, USA: Queen City Printers, 1993:272-274.

21. Consensus Committee, International Hypoxia Symposium. The Lake Louise Consensus on the Definition and Quantification of Altitude Illness. In: Sutton J, Houston CS, Coates G, eds. Hypoxia and Tountain Medicine. Burlington, USA: Queen City Printers, 1992:327-330.

22. McIntosh SE, Leemon D, Visitacion J, Schimelpfenig T, Fosnocht D. Medical incidents and evacuations on wilderness expeditions. Wilderness Environ Med 2007;18(4):298-304. http://dx.doi, rg /10.1580/07-WEME-OR-093R1.1

23. High Altitude Pulmonary Edema (HAPE). International Society for Mountain Medicine. 2016. http:// ismm.org/index.php/high-altitude-pulmonary-edema.html (accessed 9 April 2017).

24. Schimelpfenig T. NOLS Wilderness Medicine. Mechanicsburg, USA: National Outdoor Leadership chool and Stackpole Books, 2000

25. Fagenholz PJ, Gutman JA, Murray AF, Noble VE, Thomas SH, Harris NS. Chest ultrasonography for the diagnosis and monitoring of high-altitude pulmonary edema. Chest 2007;131(4):1013-1018. http:// dx.doi.org/10.1378/chest.06-1864

26. Willmann G, Gekeler F, Schommer K, et al. Update on high altitude cerebral edema including recent work on the eye. High Alt Med Biol 2014;15(2):112-122. http://dx.doi.org/10.1089/ham.2013.1142

27. Luks AM. Which medications are safe and effective for improving sleep at high altitude? High Alt Med Biol 2008;9(3):195-198. http://dx.doi.org/10.1089/ham.2008.1025

28. International Society for Mountain Medicine. Treating acute mountain sickness. 2016. http://ismm. org/index.php/treating-ams.html (accessed 9 April 2017).

29. Gertsch JH, Lipman GS, Holck PS, et al. Prospective, double-blind, randomized, placebo-controlled comparison of acetazolamide versus ibuprofen for prophylaxis against high altitude headache: The headache evaluation at altitude trial (HEAT). Wilderness Environ Med 2010;21(3):236-243. http:// dx.doi.org/10.1016/j.wem.2010.06.009

30. Lipman GS, Eifling KP, Ellis MA, et al. Wilderness Medical Society practice guidelines for the prevention and treatment of heat-related illness: 2014 update. Wilderness Environ Med 2014;25( Suppl 4):S55-S65. http://dx.doi.org/10.1016/j.wem.2014.07.017

31. Pandit A, Karmacharya P, Pathak R, Giri S, Aryal MR. Efficacy of NSAIDs for the prevention of acute mountain sickness: A systematic review and meta-analysis. J Community Hosp Intern Med Perspect 2014;4(4). http://dx.doi.org/10.3402/jchimp.v4.24927

32. International Society for Mountain Medicine. High altitude cerebral edema (HACE). 2016. http:// ismm.org/index.php/high-altitude-cerebral-edema (accessed 9 April 2017).

33. Stream JO, Grissom CK. Update on high-altitude pulmonary edema: Pathogenesis, prevention, and treatment. Wilderness Environ Med 2008;19(4):293-303. http://dx.doi.org/10.1580/07-WEME-REV-173.1 4. Zafren K. Prevention of high altitude illness. Travel Med Infect Dis 2014;12(1):29-39. http://dx.doi. org/10.1016/j.tmaid.2013.12.002

35. Davis PR, Pattinson KT, Mason NP, Richards P, Hillebrandt D. High altitude illness. J R Army Med Corps 2005;151(4):243-249. 